\title{
UARM Effective Route for Cu- and Zn-MOFs as Highly Efficient Adsorbents Towards Arsine (AsH3) Gas Adsorption: Design and a Systematic Study
}

\section{Taher Shahriari}

Birjand University of Medical Sciences

\section{Parya Kazemzadeh}

Lorestan university

\section{Malihe Zeraati}

Shahid Bahonar University of Kerman

ghasem sargazi ( $\sim$ g.sargazi@gmail.com )

Bam University of Medical Sciences

\section{Research Article}

Keywords: UAIM method, Cu/Zn-MOF nanostructures, 2k-1 factorial design, Arsine gas adsorption

Posted Date: April 14th, 2021

DOl: https://doi.org/10.21203/rs.3.rs-411190/v1

License: (9) (1) This work is licensed under a Creative Commons Attribution 4.0 International License. Read

Full License 


\section{Abstract}

Since it is essential to select the adsorbents, which are prepared with fast, environmentally friendly, and affordable methods, therefore, in this study, the $\mathrm{Cu}$ - and $\mathrm{Zn}$ - metal organic framework nanostructures were synthesized in the shortest route with the high efficiency by the effective method of ultrasonic assisted inverse micelle (UAIM) method. The synthesized samples were used as the new adsorbents in the arsine gas adsorption. The physicochemical properties of the products were examined in detail, so that the adsorbent dosage, temperature and pressure for the preparation of samples with distinctive characteristics were 0.05 $\mathrm{mg}, 25.00^{\circ} \mathrm{C}$, and $5.00 \mathrm{bar}$, respectively. Since the design and control of experimental parameters to find the best conditions for producing the samples with high adsorption efficiency is essential in this process, thus, for this purpose, fractional factorial design and response surface methodology were used. The results indicated the high efficiency of arsine gas adsorption for the synthesized samples in optimized conditions. The differences between arsine gas adsorption in this study in comparison with the previous studies could be due to the characteristic's improvement using the effective synthetic methods as well as the systematic study of experimental parameters.

\section{Introduction}

Metal organic framework (MOF) are an important category of polymer nanomaterials having applied potential in various fields such as energy storage, adsorption, separation and catalyst, with regard to morphology and other physicochemical properties [1]. These compounds are made of flexible linker and core clusters. Among the various organic linkers developed for the synthesis of MOF, the carboxylic groups have been used due to rigid structure, variety of coordination modes, and porosity as an appropriate option for the formation of the framework [2, 3].

The experimental conditions of the production process play a crucial role in the properties of the products. Today, although the porous nanomaterials are made with different techniques such as hydrothermal, mechanochemical, solvothermal, and conventional methods, but the control of synthetic parameters has been in particular attention by fast, effective and controllable ultrasonic and inverse micelle methods. On the other hand, the effects of synthetic parameters on morphology and crystalline size distributions, which affect their efficiency considering various economic aspects of the process, are particularly important [4-6] .

Arsine $\left(\mathrm{AsH}_{3}\right)$ is a pollutant gas, which regarding to the environmental effects, it is particularly important for its adsorption with high efficiency [7]. Hence, many nanostructures including carbon materials, zeolite and metal nanoparticles have been used in recent years. The results show that MOFs have been considered for distinct characteristics such as high surface area, significant porosity, and structural flexibility compared to other compounds. Moreover, the MOFs have empty sites for adsorption interactions with various gases $[8,9]$.

Although, the adsorption efficiency in these compounds is affected by the pore volume, surface area, and crystallization aspects, but improving the gas adsorption performance is a deep challenge [10]. In general, each MOF, as the distinct adsorbent, relied on the unique synthesis methodology and control the experimental adsorption parameters. The results of our investigations showed that a little attention has been paid to the relationship between the experimental systematic studies and production of high efficiency adsorbents in 
previous studies [11]. Since the experimental parameters such as adsorbent dosage, temperature and pressure, as well as their interactions have a great impact on the adsorption rate, therefore, finding the best experimental conditions using systematic studies that improve the properties of the products is particularly important [12]. Moreover, choosing an appropriate type of MOF is highly important [13]. The results show that the metal series of M-MOF, in which M represents the metal ions such as copper and cobalt, have a high potential for gas adsorption $[14,15]$.

In this study, the inverse micelle (IM) and ultrasonic assisted inverse micelle (UAIM) methods were used for synthesis of two stable MOFs including copper and zinc with various particle size distribution, surface area, and porosity, and the effective parameters in synthesis such as surfactant content, time duration, temperature and power of ultrasonic were optimized. The synthesis products have been evaluated for being used as the arsine gas adsorbents. The effects of experimental parameters such as adsorbent dosage, temperature and pressure on the gas adsorption rate were systematically studied and designed by fractional factorial design.

\section{Experimental Section}

\subsection{Materials and instrumentation}

Copper (II) nitrate hexzahydrate (MW:187.56 g/mol, 99.90\%), and Zinc (II) nitrate hexzahydrate (MW: 297.48 $\mathrm{g} / \mathrm{mol}, 99.80 \%$ ) were purchased from Merck. ligand agent as 2,6-Pyridinedicarboxylic acid (MW: $167.12 \mathrm{~g} / \mathrm{mol}$, $99.99 \%$ ) and surfactant agent as a sodium dodecyl sulfate (SDS) were purchased from Sigma Aldrich. All materials were used as received, without further purification. X-ray diffraction (XRD) patterns were used in reflection mode using a powder X-ray diffractometer (X'Pert MPD, PANanalytical, Cu Ka radiation, $\lambda=0.154$ $\mathrm{nm}$ ) between 10" and 90" (2-Theta) with a step width of "0.010". For scanning electron microscopy (SEM), the MOF nanostructures were coated with Au/Pd using a Denton Vacuum Desk II )New Jersey, USA(. The coated samples were then imaged using a LEO 1500 with a field emission gun operating at $12 \mathrm{keV}$. The Fourier transform infrared spectroscopy (FT-IR) spectra of the Cu and Zn-MOF samples have been recorded between 4000 and $500 \mathrm{~cm}^{-1}$ as KBr pellets on SHIMADZU FT-IR 8400 Spectrometer (Kyoto, Japan). Pore textural properties including surface area and porosities were measured with an $\mathrm{N}_{2}$ adsorption technique (Belsorp mini II (Osaka, Japan)) at $77 \mathrm{~K}$.

\subsection{Syntheses of $\mathrm{Cu}$ and Co-MOFs 2.2.1. Inverse micelle (IM) method}

$\mathrm{Cu}$ and $\mathrm{Zn}$-MOFs syntheses using IM procedure were as follows: the solutions of cupper (II) nitrate hexahydrate $(0.068 \mathrm{~g}$ in $21 \mathrm{~mL}$ distilled water) and zinc (II) nitrate hexahydrate $(0.068 \mathrm{~g}$ in $18 \mathrm{~mL}$ distilled water) were prepared in $0.040 \mathrm{~g}$ of 2,6-Pyridinedicarboxylic acid. The resulted solutions were then added to a mixture containing $0.032 \mathrm{mmol}$ of surfactant (sodium dodecyl sulfate) and $14 \mathrm{~mL}$ of $\mathrm{n}$-hexane. The final mixtures were then stirred at $60{ }^{\circ} \mathrm{C}$ for $15 \mathrm{~min}$. After $60 \mathrm{~min}$, the green and white crystals of $\mathrm{Cu}$ and $\mathrm{Zn}$ - MOF were formed, respectively.

\subsubsection{Ultrasonic assisted inverse micelle (UAIM) method}


In a typical UAIM process, the solution obtained in the previous sections was entered into the ultrasound reactor and undergoes optimal conditions of ultrasound irradiation (time duration: $25 \mathrm{~min}$, temperature: $35^{\circ} \mathrm{C}$ and power of ultrasound: $210 \mathrm{~W}$ ). After $25 \mathrm{~min}$, the corresponding crystals of $\mathrm{Cu}$ and $\mathrm{Zn}$ - MOF nanostructures were isolated. The schematic representation route for synthesis of samples is showed in Fig. 1.

\subsection{Arsine gas adsorption procedure}

To investigate the arsine adsorption by MOF nanostructures, a setup composed of different parts was developed (Fig. 1). Where P, N, R, T, and Z present gas pressure, number of gas moles, general constant of gases, equilibrium temperature, and compressibility coefficient in dozer, respectively. Finally, the gas moles adsorbed by $Z n-M O F$ nanostructures can be calculated by $n_{A D S}=n_{1}-n_{2}$. The compressibility parameters $\left(Z_{1}\right.$, $Z_{2}$ ) was calculated according to methodology of our previous study [16].

\section{Results And Discussion}

\subsection{Effective synthesis procedure}

Fig. 3 indicates the SEM images of $\mathrm{Cu}$ and $\mathrm{Zn}$ - MOF samples, which have been synthesized by the IM and UAIM methods. In samples $\boldsymbol{A}$ and $\boldsymbol{C}$, which are synthesized by the IM method, the particles have a tendency for severe agglomeration, which caused non-uniform morphology with a spherical shape in the structures. Also, the particle size distribution in these samples is in the bulk range. Although, the evidence of particle agglomeration can be seen in some cases of the samples synthesized by the UAIM method, but the dominant distribution of these particles is uniform (Fig. $B$ and $\boldsymbol{D}$ ). The morphology of these compounds is more likely rod-shaped in comparison with the samples synthesized by IM method. These images represent the less mean particle size distribution in the UAIM method than the IM method, so that the $\mathrm{Cu}$ and $\mathrm{Zn}$ - MOF samples synthesized by this method have mean particle size of 35 and $45 \mathrm{~nm}$, respectively. According to the conditions used to synthesize these samples, it seems that the UAIM method leads to less particle size distribution, synthesis of samples with minimum agglomeration and uniform morphology. The homogenous morphology and small particle size distribution of the $\mathrm{Cu}$ - and $\mathrm{Zn}$ - MOF nanostructures developed by UAIM procedure in this method are remarkable compared to previous samples $[17,18]$. Therefore, the UAIM has been chosen as an appropriate and effective technique compared to IM for the synthesis of the metal organic framework nanomaterials.

\subsection{Structural formula}

Fig. 4 shows the XRD patterns of $\mathrm{Cu}$ and $\mathrm{Zn}$ - MOF samples synthesized in optimal condittioms of UAIM methods. These patterns properly show the formation of Cu-MOF (JCPDS cards.no: 05-0661) and Zn-MOF (JCPDS cards.no: 234578). In both patterns, the wider and intense peaks in comparison with samples that have been already synthesized by different methods, are the strong evidence for the smaller crystalline sizes of the $\mathrm{Cu}$ and $\mathrm{Zn}$ - MOF samples synthesized in the present study $[15,19]$. Regarding the UAIM method used in this study, it seems that this novel method has produced samples with desirable crystallographic properties. Furthermore, according to the data indexed from the XRD patterns, $\mathrm{Cu}$ and $\mathrm{Zn}$ - MOF samples have monoclinic and cubic crystallin structures, respectively. 
The Co- and Cu-MOF samples synthesized by two different methods were characterized using the FTIR spectra (Fig. 5). In both samples, the absorption band at 3400 to $3500 \mathrm{~cm}^{-1}$ may be attributed to the coordinated water in the products [20]. The frequency peaks at $3000 \mathrm{~cm}^{-1}$ are ascribed to the stretching vibration of aromatic C-H. The absorption peak observed near 2600 to $2500 \mathrm{~cm}^{-1}$ confirms the presence of COO- groups of the ionized ligand and the peak around 1400 to $1200 \mathrm{~cm}^{-1}$ is related to C-N bonds [21]. The absorption band near $900 \mathrm{~cm}^{-1}$ is corresponded to the asymmetric and symmetric stretching vibrations of aliphatic $\mathrm{CH}$ and the peaks at 400 to $600 \mathrm{~cm}^{-1}$ are assigned to the $\mathrm{Cu}$ - and $\mathrm{Zn}-\mathrm{O}$ bonds. Based on results obtained from FTIR spectra and according to different configurations of the linkers [22], the structures of Figure 6 were suggested for $\mathrm{Cu}$ - and Zn-MOF nanostructures samples.

\subsection{Desirable MOF-adsorbent}

According to the $\mathrm{N}_{2}$ adsorption/desorption isotherms shown in Fig. 7, the Cu-MOF sample exhibited type I isotherm indicates the microporous distribution of pores [23], whereas the isotherms of Zn-MOF sample are similar to the type III, which shows the mesoporous behaviour in this sample [24]. According to the results of the BET technique, the Cu-MOF sample has a surface area of $410 \mathrm{~m}^{2} / \mathrm{g}$ with volume pore of $0.021 \mathrm{~cm}^{3}$, while the corresponding values for Zn-MOF were $1145 \mathrm{~m}^{2} / \mathrm{g}$ and $0.097 \mathrm{~cm}^{3}$, respectively.

The BJH method also approves the microporous and mesoporous distribution for Cu- and Zn-MOF samples, respectively. So, in accordance to the information obtained from this method, the mean pore size is $1.94 \mathrm{~nm}$ for Cu-MOF and $2.59 \mathrm{~nm}$ for Zn-MOF sample (See Fig. 8). Although, the synthesis technique developed for these samples is the same, but the cause of differences in the textural properties of these samples can be attributed to the type of applied MOF, and as a result, the variety of structural configurations that were discussed in the previous section. Since choosing the adsorbents with desirable textural properties is particularly important, thus, the Zn-MOF nanostructures synthesized in this study were selected as a novel candidate in order to study adsorption applications for Arsine gas adsorption.

\subsection{Experimental design}

Zn-MOF samples synthesized by the UAIM method, with regard to distinctive features, were used as a novel candidate for arsine gas adsorption. The adsorption studies of the process underwent systematic design using fractional factorial method. Since the gas adsorption process was studied by volumetric method, thus, the effective factors (Table 1) of which were selected based on previous studies including adsorbent dosage $(\boldsymbol{A})$, temperature $(\boldsymbol{B})$ and pressure $(\boldsymbol{C})[25]$. Considering these experimental parameters, 18 runs were carried out, and the resulting adsorption responses are shown in Table 2 (Each experiment was performed two replicates).

\section{Table 1. Coded and uncoded levels of adsorbent dosage, temperature and pressure of UAIM method for fractional factorial design.}




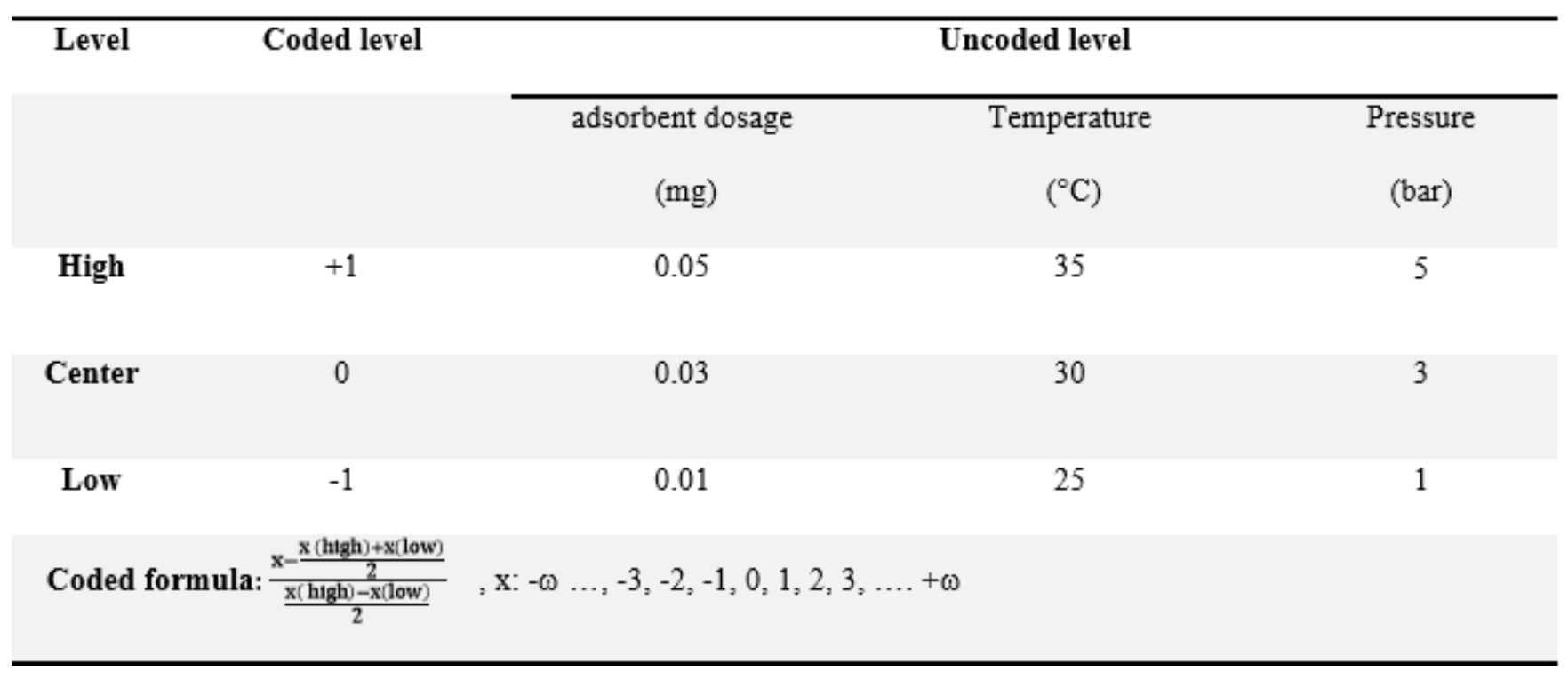

Table 2: Randomized complete fractional factorial design for arsine gas adsorption experiments of Zn-MOF prepared by UAIM method. 


\begin{tabular}{|c|c|c|c|c|c|c|c|}
\hline $\begin{array}{l}\text { Sample } \\
\text { (Level) }\end{array}$ & $\begin{array}{l}\text { Std } \\
\text { order }\end{array}$ & Center Pt & $\begin{array}{l}\text { A } \\
(\mathrm{mg})\end{array}$ & $\begin{array}{l}\text { B } \\
\left({ }^{\circ} \mathrm{C}\right)\end{array}$ & $\begin{array}{l}\text { C } \\
\text { (bar) }\end{array}$ & REP & $\begin{array}{l}\text { Adsorption } \\
\text { (mmol/g) }\end{array}$ \\
\hline \multirow[t]{2}{*}{ a } & 9 & 1 & +1 & +1 & -1 & 1 & 64.4 \\
\hline & & & & & & 2 & 4.2 \\
\hline \multirow[t]{2}{*}{ b } & 5 & 1 & -1 & +1 & 0 & 1 & 73.8 \\
\hline & & & & & & 2 & 3.9 \\
\hline \multirow[t]{2}{*}{ c } & 6 & 1 & -1 & 0 & -1 & 1 & 5.2 \\
\hline & & & & & & 2 & 5.3 \\
\hline \multirow[t]{2}{*}{ d } & 3 & 1 & 0 & 0 & +1 & 1 & 7.1 \\
\hline & & & & & & 2 & 6.8 \\
\hline \multirow[t]{2}{*}{ e } & 2 & 0 & +1 & -1 & 1 & 1 & 8.2 \\
\hline & & & & & & 2 & 8.3 \\
\hline \multirow[t]{2}{*}{$f$} & 8 & 1 & 0 & +1 & -1 & 1 & 3.1 \\
\hline & & & & & & 2 & 2.0 \\
\hline \multirow[t]{2}{*}{ g } & 4 & 1 & 0 & -1 & 1 & 1 & 8.1 \\
\hline & & & & & & 2 & 8.0 \\
\hline \multirow[t]{2}{*}{ h } & 7 & 1 & -1 & +1 & -1 & 1 & 1.7 \\
\hline & & & & & & 2 & 1.4 \\
\hline \multirow[t]{2}{*}{ i } & 1 & 1 & +1 & 0 & +1 & 1 & 7.8 \\
\hline & & & & & & 2 & 7.6 \\
\hline
\end{tabular}

\subsection{Systematic study of procedure}

Fig. 9 shows a different residual plot for adsorption studies of the Zn-MOF samples. Since the positive and negative levels are approximately equal in all of these plots, thus, it is concluded that dispersions of adsorption experiments are quite randomized and chance of each one is equal to another. The above cases approve the scientific design of experiments for adsorption studies [26].

The analysis of variance is used in order to study the effects of different experimental parameters including temperature, adsorbent, and pressure on adsorption response. As reported in Table 3, although all three studied parameters affect the arsine gas adsorption, but with regard to $\boldsymbol{P}_{\text {values }}$ obtained for each, the effect of temperature is more significant than the other parameters. Also, the effects of experimental parameters and the interaction among them are confirmed by Pareto charts in Fig. 10. 
According to the arsine adsorption results reported in Table 2, conditions $\boldsymbol{e}, \boldsymbol{g}$ with highest adsorption rate were selected as optimal conditions. Although, the adsorption rate in condition $\boldsymbol{e}$ is higher than condition $\boldsymbol{g}$, but the difference has not such an impact on adsorption results. Regarding the effect of pressure on gas adsorption, which has been evaluated in earlier studies, since the lowest value is selected for pressure in conditions $\boldsymbol{f}$ and $\boldsymbol{h}$, thus, the arsine gas adsorption is significantly reduced. In conditions $\boldsymbol{a}$ and $\boldsymbol{b}$, with same temperature and different adsorbent and pressure, the adsorption results show the high arsine adsorption rate for condition $\mathbf{a}$. Since in this case, the adsorbent rate is greater than the pressure, thus, the difference in the adsorbent dosage has a more effect on the adsorption. This difference is in accordance with the results of the analysis of variance, which approves the great effect of the adsorbent dosage than the pressure. The adsorption values in $\boldsymbol{c}, \boldsymbol{d}$, and $\boldsymbol{i}$ are varied depending on the difference in values of experimental parameters in these cases compared to the optimal conditions.

\section{Table 3 Analyses of variance for arsine gas adsorption of Zn-MOF samples synthesized by UAIM method.}

\begin{tabular}{|llllll|}
\hline Source & DF & Seq SS & Adj SS & Adj MS & $P_{\text {value }}$ \\
\hline A & 1 & 93.924 & 88.5639 & 29.5213 & 0.004 \\
\hline B & 1 & 86.44 & 66.97 & 25.14 & 0.01 \\
\hline C & 1 & 68.09 & 36.78 & 13.42 & 0.04 \\
\hline A*B & 1 & 49.57 & 20.12 & 17.39 & 0.06 \\
\hline A*C & 1 & 79.14 & 59.12 & 19.74 & 0.03 \\
\hline B*C & 1 & 87.45 & 69.22 & 27.41 & 0.009 \\
\hline R-Sq: $97.24 \%$ R-Sq(pred): $99.05 \%$ R-Sq(adj): 98.44\% \\
\hline \multicolumn{7}{|l}{} \\
\hline
\end{tabular}

\subsection{Optimization parameters}

Regarding the fractional factorial design evaluated in this study and taking into account the regression equations obtained as an output, three-dimensional images are shown in Fig. 11, which show the relationship between experimental parameters related to the arsine gas adsorption process. These images are in good agreement with the results of Table 2 . With respect to the regression equation of adsorption (ADS: 1158-514A-686B-500C+44D), we able to conclude that the proposed theoretical model of this study confirms the experimental results presented in Table2.

Since the purpose of this study is to find adsorbents with high adsorption rates, RSM optimization has been used, and values for each of the experimental parameters (adsorbent dosage, temperature and pressure) with the desirability of 0.9 were depicted in Fig. 12. According to the formula described in Table 1, these values are converted to non-coded values which data is reported in Table 3. By comparing the predicted values of arsine gas adsorption by RSM with previous samples, it seems that the adsorbents developed in this study have a higher adsorption rate than recently adsorbent such as carbon materials [27], graphene oxide [28], copperexchanged zeolite [29], monolayer $\mathrm{MoS}_{2}$ [30], $\mathrm{Hf}_{2} \mathrm{CO}_{2}$ monolayer [7] and carbon nanotubes [31] (Fig. 13). Increasing the efficiency of Zn-MOF sample developed in this study are related to the systematic studies as 
well as optimization procedure which these superiorities could distinguish these adsorbents from previous adsorbents.

Table 4 Response optimization the experimental parameters for Arsine gas adsorption obtained by RSM results.

\begin{tabular}{|lllllllllll|}
\hline Response & Goal & Lower & Target & Upper & \multicolumn{2}{l}{$\begin{array}{l}\text { Experimental } \\
\text { parameters }\end{array}$} & & Desirability & $\begin{array}{l}\text { Predict } \\
\text { response } \\
\text { value }\end{array}$ \\
& & & & & & A & B & C & & \\
& & & & & $(\mathrm{mg})$ & $\left({ }^{\circ} \mathrm{C}\right)$ & $(\mathrm{bar})$ & & \\
$\begin{array}{l}\text { Adsorption } \\
\text { (mmol/g) }\end{array}$ & maximize & 8.20 & 9.00 & 12.00 & 0.032 & 25.00 & 4.34 & 0.9071 & 8.74 \\
\hline
\end{tabular}

\section{Conclusion}

In this research, two samples of $\mathrm{Cu}$ - and $\mathrm{Zn}$ - metal organic frameworks with various physicochemical properties were synthesized by UAIM method. This strategy proposed the chance of producing new nanostructures in the shortest time with uniform morphology, high surface area, and large volume pore. The final products were selected as arsine gas adsorbents, and the effects of adsorbent, temperature, and pressure were systematically studied by fractional factorial design. The experimental results showed that the nanomaterials synthesized in this study had a high adsorption rate compared to other adsorbents, so an effective synthesis method as well as the systematic studies of experimental parameters can play a key role to increase their efficiency. These synthesized nanoadsorbents proposed can be open a new window as highefficiency adsorbents, and may extended to different applications.

\section{Declarations}

\section{Conflict of Interest}

The authors declare no conflict of interest in this study

\section{Availability of data and material}

The authors confirm the Availability of data and material

\section{Compliance with ethical standards}

The manuscript is in compliance with ethical standards

\section{Consent to participate}

All of the authors confirm the consent to participate

\section{Consent for Publication}


All of the authors confirm the consent for Publication

\section{ACKNOWLEDGEMENT}

The authors would like to acknowledge from the Bam University of Medical Sciences

\section{References}

1. Nadar, S.S., et al., Polysaccharide based metal organic frameworks (polysaccharide-MOF): A review. Coordination Chemistry Reviews, 2019. 396: p. 1-21.

2. Al-Rowaili, F.N., et al., A review on recent advances for electrochemical reduction of carbon dioxide to methanol using metal-organic framework (MOF) and non-MOF catalysts: challenges and future prospects. ACS Sustainable Chemistry \& Engineering, 2018. 6(12): p. 15895-15914.

3. Goetjen, T.A., et al., Metal-organic framework (MOF) materials as polymerization catalysts: a review and recent advances. Chemical Communications, 2020. 56(72): p. 10409-10418.

4. Remya, V. and M. Kurian, Synthesis and catalytic applications of metal-organic frameworks: a review on recent literature. International Nano Letters, 2019. 9(1): p. 17-29.

5. Soni, S., P.K. Bajpai, and C. Arora, A review on metal-organic framework: synthesis, properties and application. Characterization and Application of Nanomaterials, 2018. 2(2).

6. Winarta, J., et al., A decade of UiO-66 research: a historic review of dynamic structure, synthesis mechanisms, and characterization techniques of an archetypal metal-organic framework. Crystal Growth \& Design, 2019. 20(2): p. 1347-1362.

7. Ma, S., et al., Ab initio prediction and characterization of Hf2CO2 monolayer as a promising adsorbent to capture toxic AsH3 gas. Applied Surface Science, 2021. 535: p. 147660.

8. Sardarzadeh, S., J. Karamdel, and P. Nayebi, Adsorption of SO2, H2S, NH3, PH3, and AsH3 Gas Molecules on Pristine Armchair Phosphorene Nanoribbon: A First-Principles Study. physica status solidi (b), 2020. 257(9): p. 2000120.

9. Luo, H., et al., NH3, PH3 and AsH3 adsorption on alkaline earth metal (Be-Sr) doped graphenes: Insights from DFT calculations. Applied Surface Science, 2021. 537: p. 147542.

10. Wen, M., et al., Metal-organic framework-based nanomaterials for adsorption and photocatalytic degradation of gaseous pollutants: recent progress and challenges. Environmental Science: Nano, 2019. 6(4): p. 1006-1025.

11. Wang, Y., et al., Rational construction of an ssa-type of MOF through pre-organizing the ligand's conformation and its exceptional gas adsorption properties. Dalton Transactions, 2018. 47(7): p. 24442452.

12. Petit, C., Present and future of MOF research in the field of adsorption and molecular separation. Current opinion in chemical engineering, 2018. 20: p. 132-142.

13. Huang, K., et al., MOF-assisted synthesis of Ni, Co, Zn, and N multidoped porous carbon as highly efficient oxygen reduction electrocatalysts in Zn-air batteries. Materials Today Energy, 2021. 19: p. 100579. 
14. Abedini, H., A. Shariati, and M.R. Khosravi-Nikou, Adsorption of propane and propylene on M-MOF-74 (M= Cu, Co): equilibrium and kinetic study. Chemical Engineering Research and Design, 2020. 153: p. 96-106.

15. Kim, H.-C., S. Huh, and Y. Kim, Selective carbon dioxide sorption by a new breathing three-dimensional ZnMOF with Lewis basic nitrogen-rich channels. Dalton Transactions, 2018. 47(14): p. 4820-4826.

16. Sargazi, G., et al., Chitosan/polyvinyl alcohol nanofibrous membranes: towards green super-adsorbents for toxic gases. Heliyon, 2019. 5(4): p. e01527.

17. Zhao, C., et al., A Zn-MOF with 8-fold interpenetrating structure constructed with N, N'-bis (4carbozylbenzyl)-4-aminotoluene ligands, sensors and selective adsorption of dyes. Journal of Solid State Chemistry, 2019. 274: p. 86-91.

18. Ebrahimi, A.K., I. Sheikhshoaie, and M. Mehran, Facile synthesis of a new metal-organic framework of copper (II) by interface reaction method, characterization, and its application for removal of malachite green. Journal of Molecular Liquids, 2017. 240: p. 803-809.

19. Zhong, Z., et al., Synthesis and characterization of mesoporous Cu-MOF for laccase immobilization. Journal of Chemical Technology \& Biotechnology, 2017. 92(7): p. 1841-1847.

20. Wei, M., X. Wang, and X. Duan, Crystal Structures and Proton Conductivities of a MOF and Two POMMOF Composites Based on Cull lons and 2, 2'-Bipyridyl-3, 3'-dicarboxylic Acid. Chemistry-A European Journal, 2013. 19(5): p. 1607-1616.

21. Zhang, D.-J., et al., Hydrothermal synthesis, structure and rare ferromagnetic property of a 3-D Nd (III) metal-organic framework based on mixed pyridine-2, 5-dicarboxylic acid/nicotinic acid ligands. Inorganica Chimica Acta, 2009. 362(1): p. 299-302.

22. García-López, V., et al., Fe (II) spin crossover complexes of a derivative of 2, 6-bis (pyrazol-1-yl) pyridine (1bpp) functionalized with a carboxylic acid in the 3-pyridyl position. Polyhedron, 2019. 170: p. 95-100.

23. Ross, D.J. and R.M. Bustin, Impact of mass balance calculations on adsorption capacities in microporous shale gas reservoirs. Fuel, 2007. 86(17-18): p. 2696-2706.

24. Du, M., et al., A channel-type mesoporous In (iii)-carboxylate coordination framework with high physicochemical stability for use as an electrode material in supercapacitors. Journal of Materials Chemistry A, 2014. 2(25): p. 9828-9834.

25. Sargazi, G., et al., A novel composite derived from a metal organic framework immobilized within electrospun nanofibrous polymers: An efficient methane adsorbent. Applied Organometallic Chemistry, 2020. 34(3): p. e5448.

26. Sargazi, G., D. Afzali, and A. Mostafavi, A novel synthesis of a new thorium (IV) metal organic framework nanostructure with well controllable procedure through ultrasound assisted reverse micelle method. Ultrasonics sonochemistry, 2018. 41: p. 234-251.

27. !!! INVALID CITATION !!! \{\}.

28. Furue, R., et al., Arsine gas sensor based on gold-modified reduced graphene oxide. Sensors and Actuators B: Chemical, 2017. 240: p. 657-663.

29. Wang, X., et al., Arsine adsorption in copper-exchanged zeolite under low temperature and micro-oxygen conditions. RSC advances, 2017. 7(89): p. 56638-56647. 
30. Xu, G., G. Song, and Y. Wang, Improvement of the arsine adsorption by doping on monolayer MoS2. Functional Materials Letters, 2019. 12(04): p. 1950058.

31. Shojaie, F., Arsine adsorption on the surface of palladium-doped carbon nanotubes. Moroccan Journal of Chemistry, 2018. 6(4): p. 6-4 (2018) 676-688.

\section{Figures}

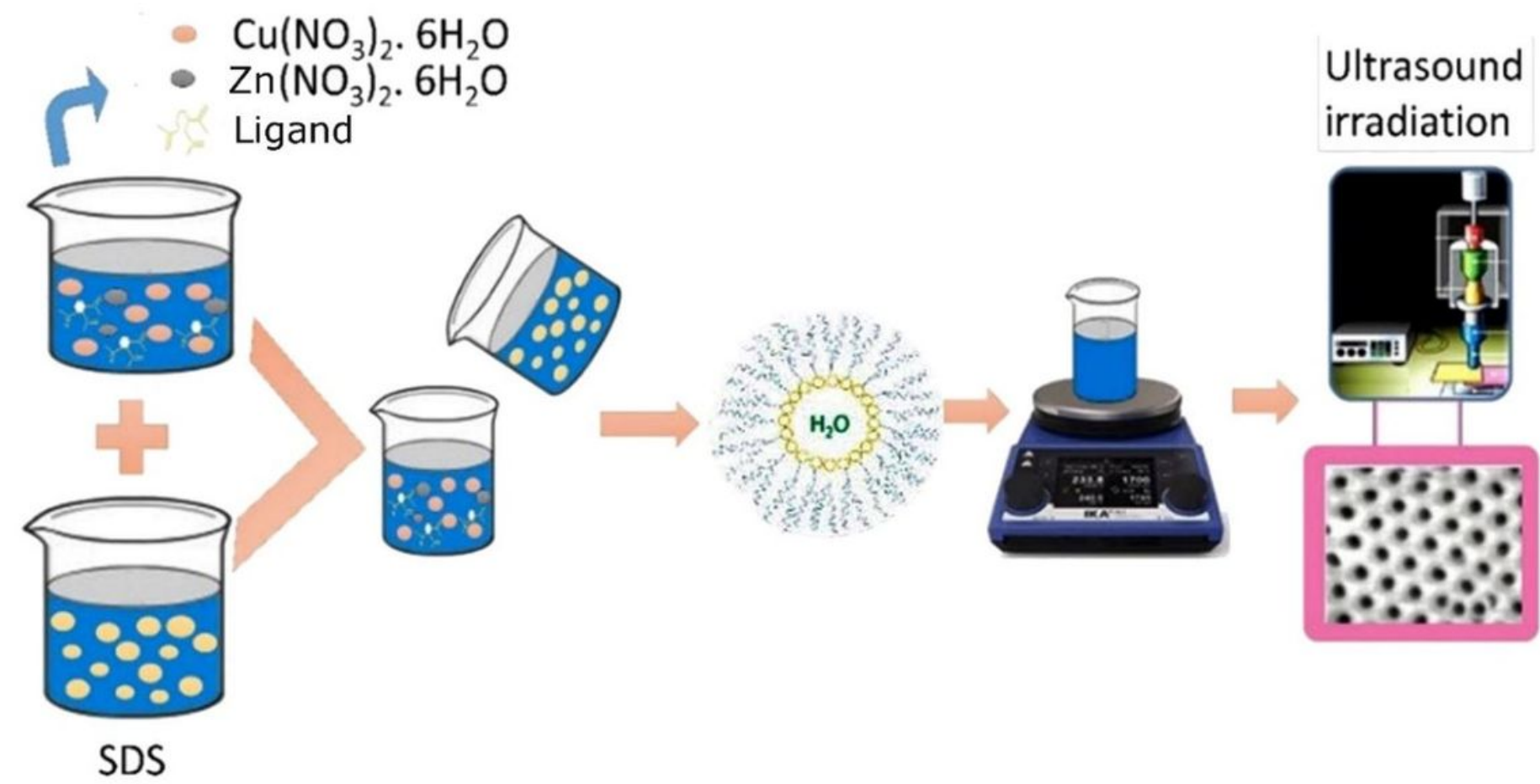

Figure 1

Schematic representation of the synthesis of Cu- and Zn-MOF nanostructures by UAIM method. 


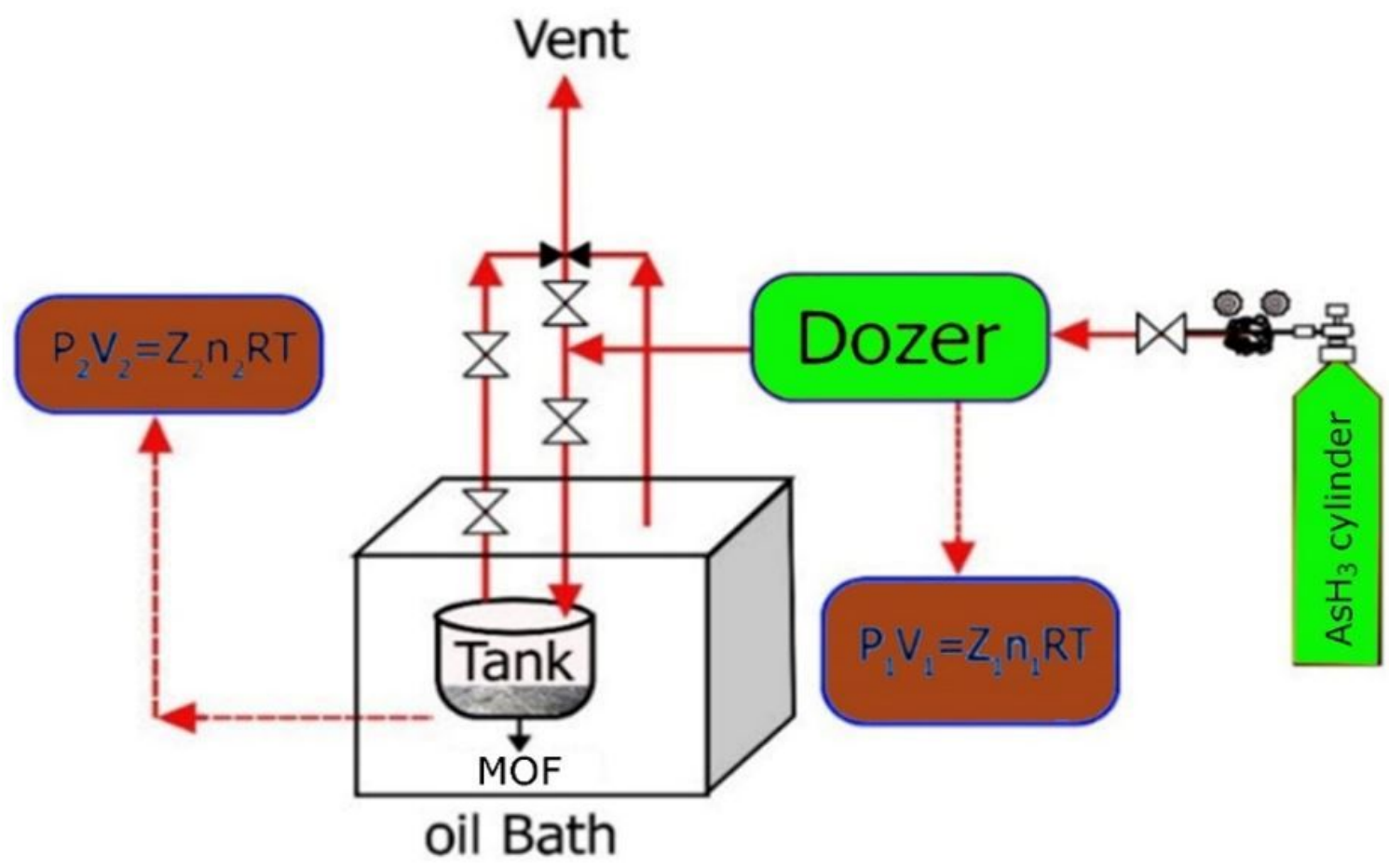

Figure 2

Schematic procedure of voltametric setup for Arsine gas adsorption. 

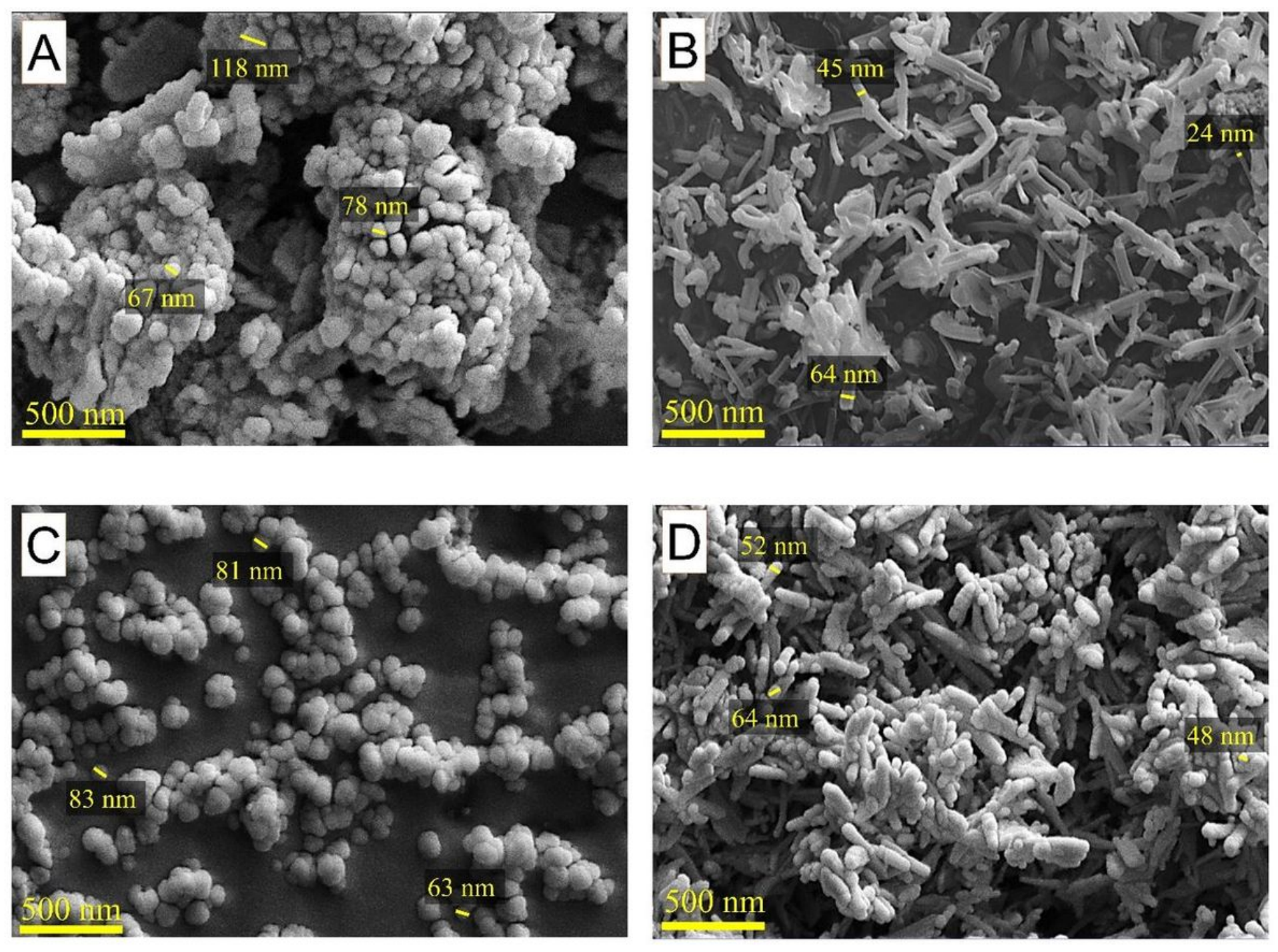

\section{Figure 3}

SEM images of the Cu-MOF and Zn-MOF (IM method: A, C; UAIM method: B and D). 


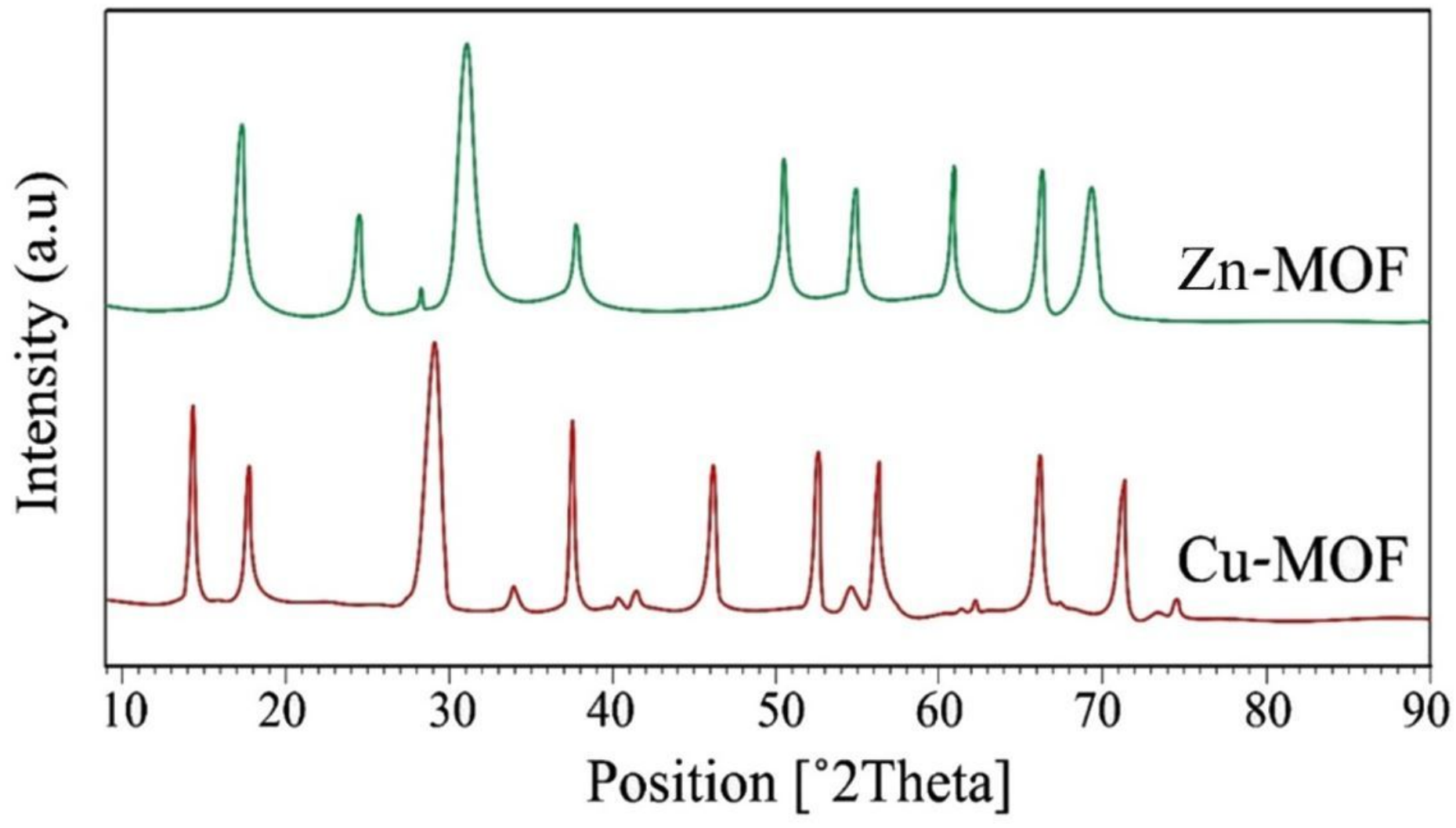

Figure 4

XRD patterns of Cu- and Zn- MOF samples synthesized by UAIM method. 

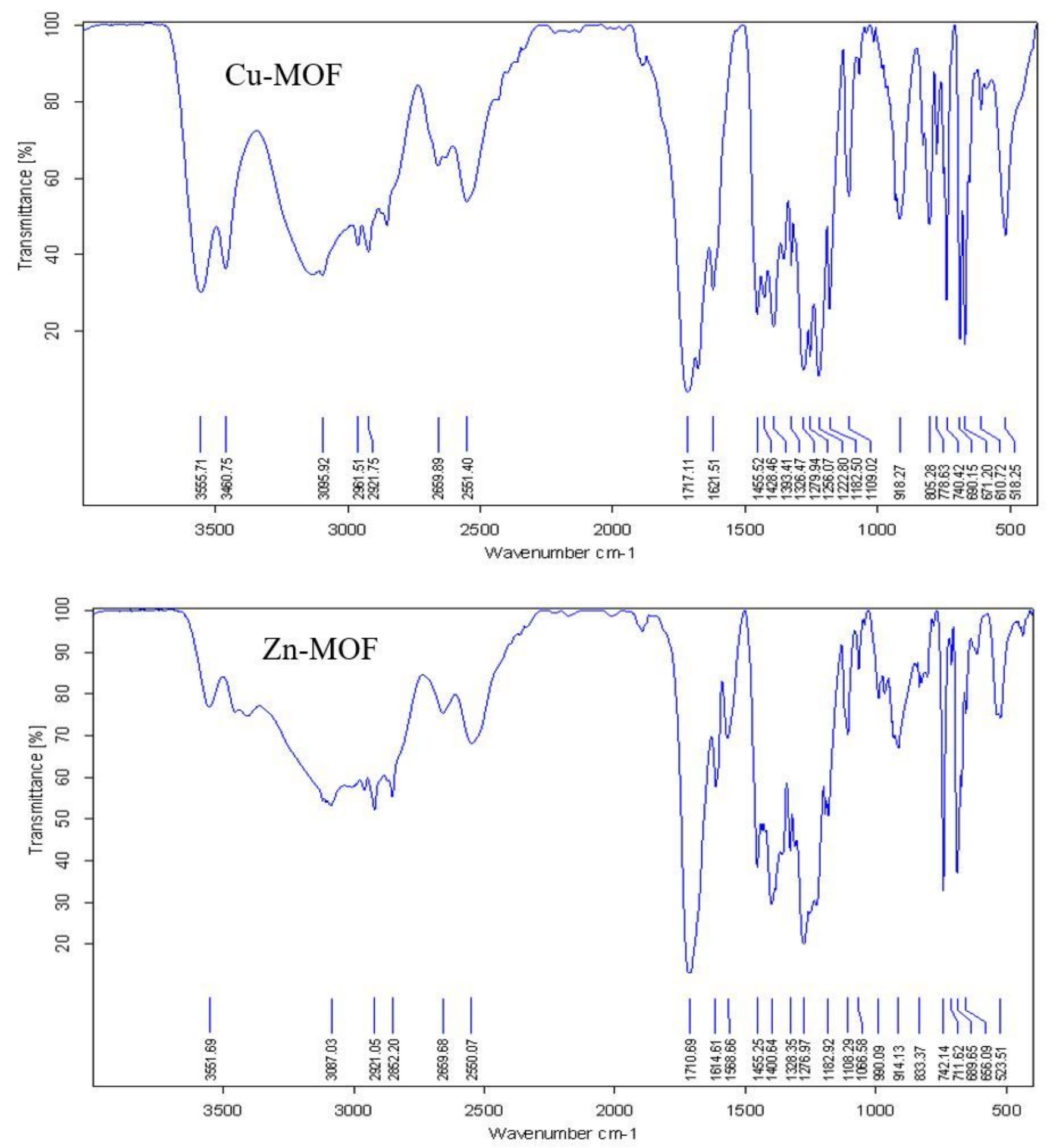

Figure 5

FTIR spectra of Cu and Zn- MOF samples prepped under optimal conditions of UAIM method. 

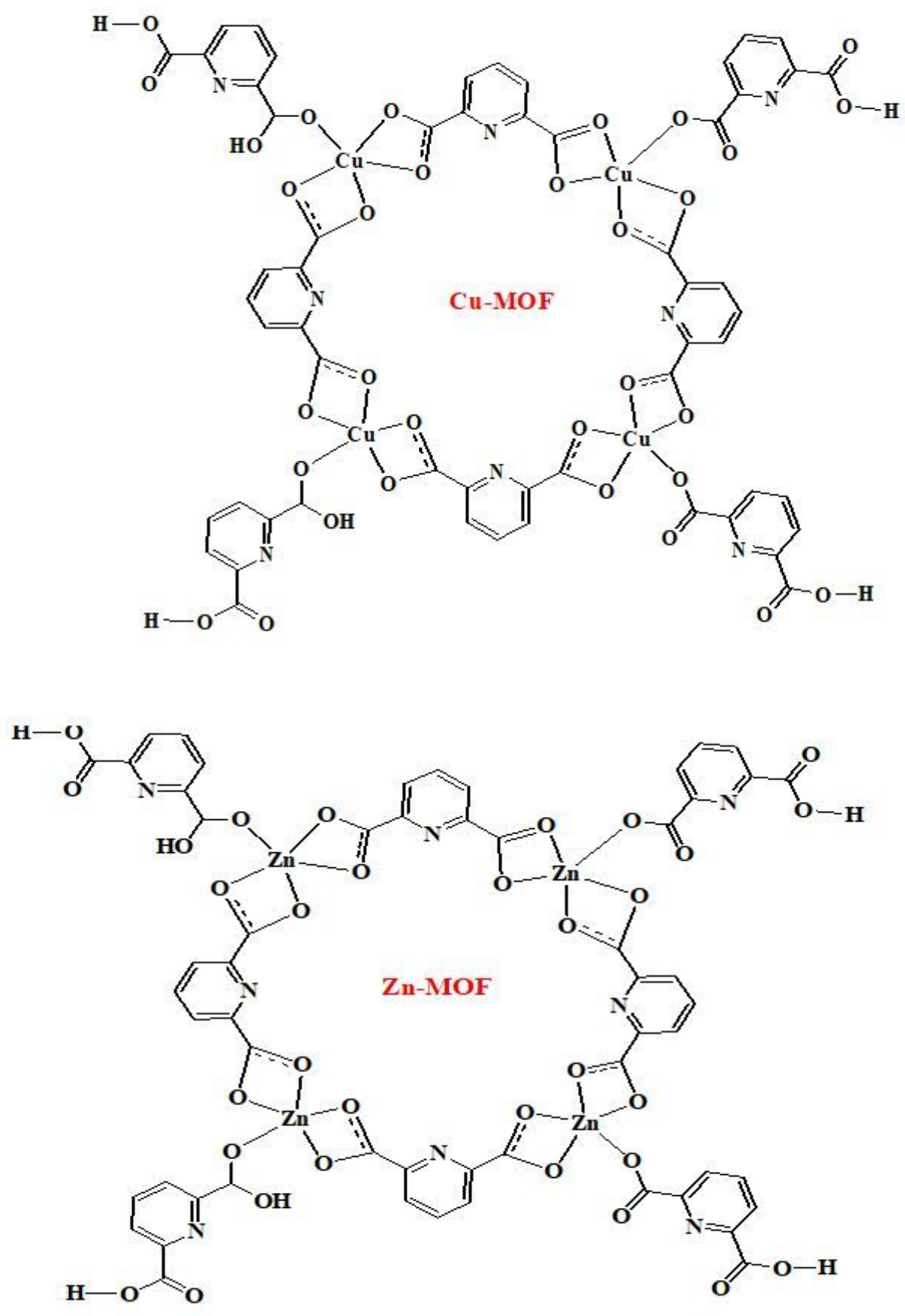

Figure 6

The suggested structure of $\mathrm{Cu}$ and $\mathrm{Zn}$ - MOF samples fabricated by UARM methods. 


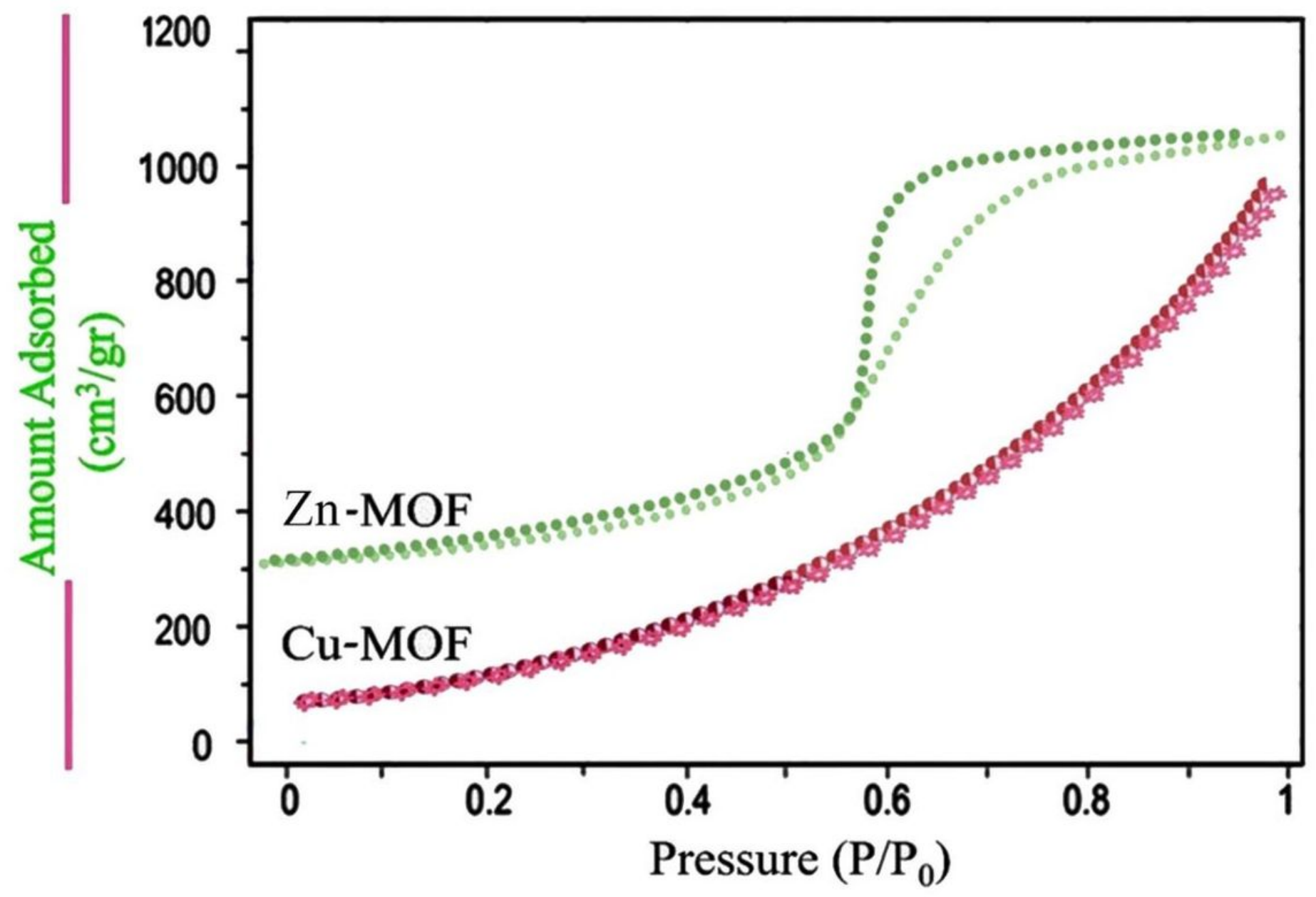

Figure 7

Adsorption/desorption isotherms of $\mathrm{Cu}$ - and Zn-MOF samples synthesized by UAIM method. 


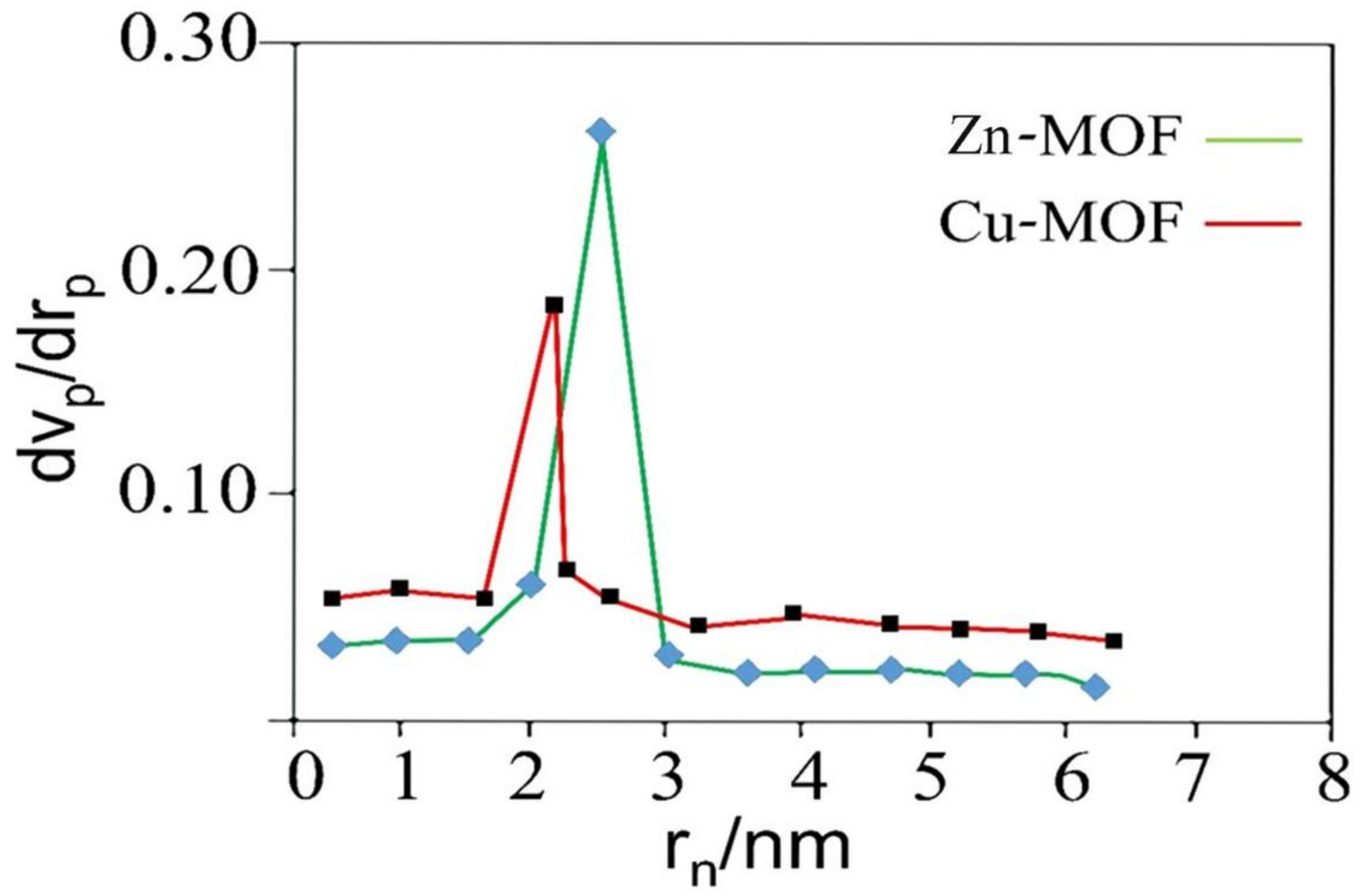

Figure 8

Pore size distributions of of $\mathrm{Cu}$ - and Zn- MOF samples obtained from BJH method. 


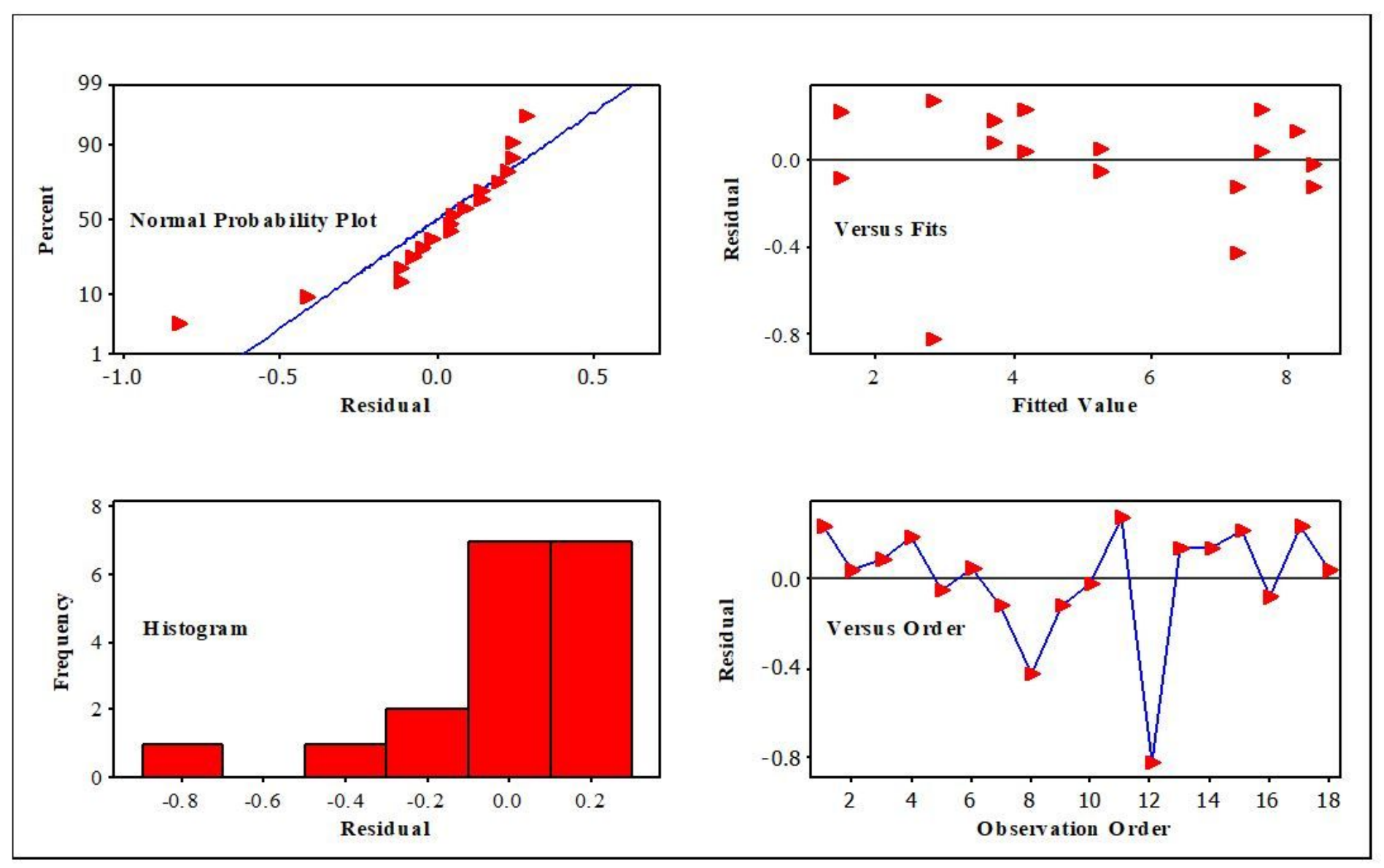

Figure 9

Normal probability plots for arsine gas adsorption by Zn-MOF sample. 


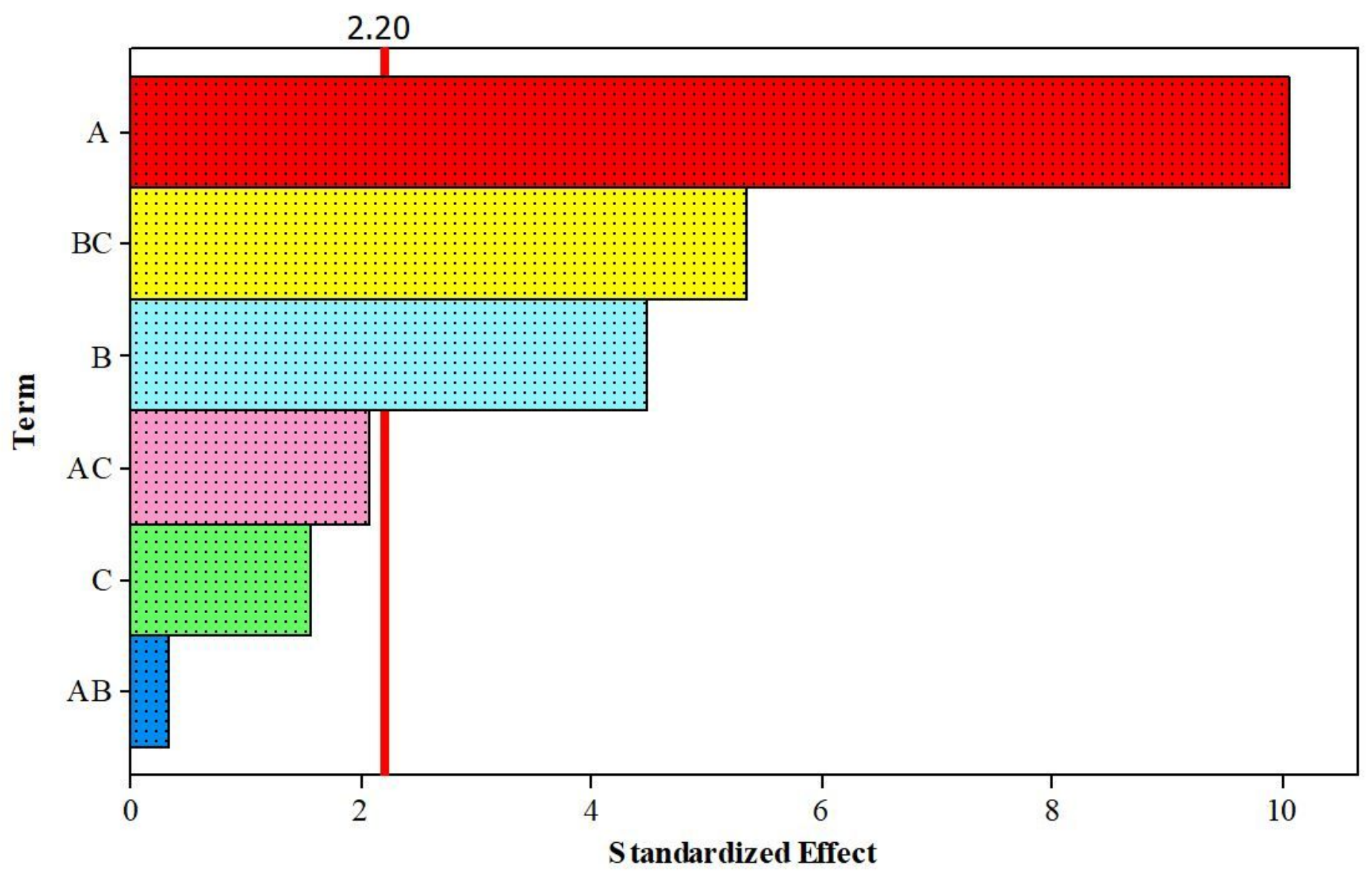

Figure 10

Pareto charts for Arsine gas adsorption of Zn-MOF sample. 


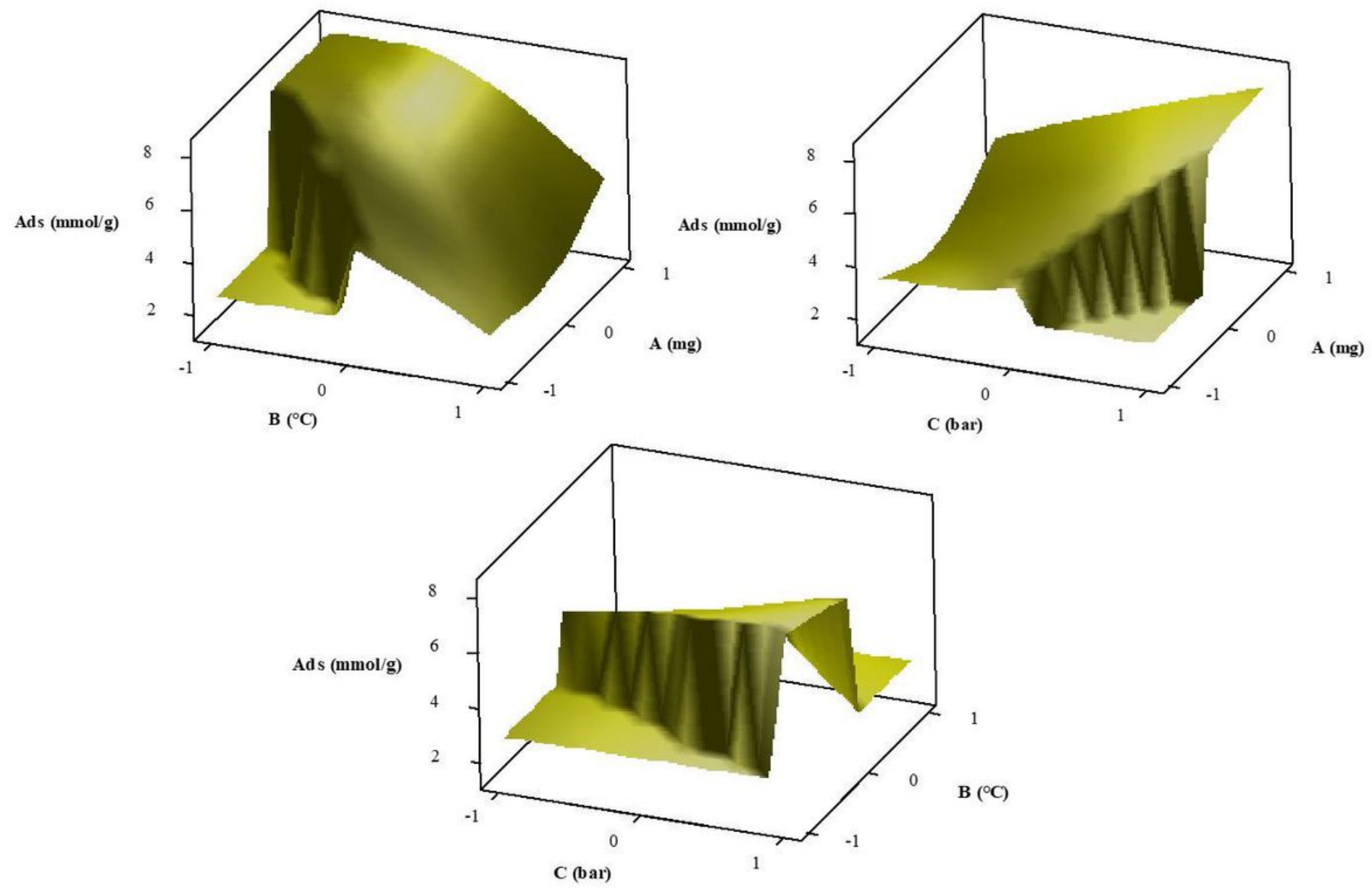

Figure 11

Surface plots for arsine gas adsorption of Zn-MOF obtained from a regression model. 


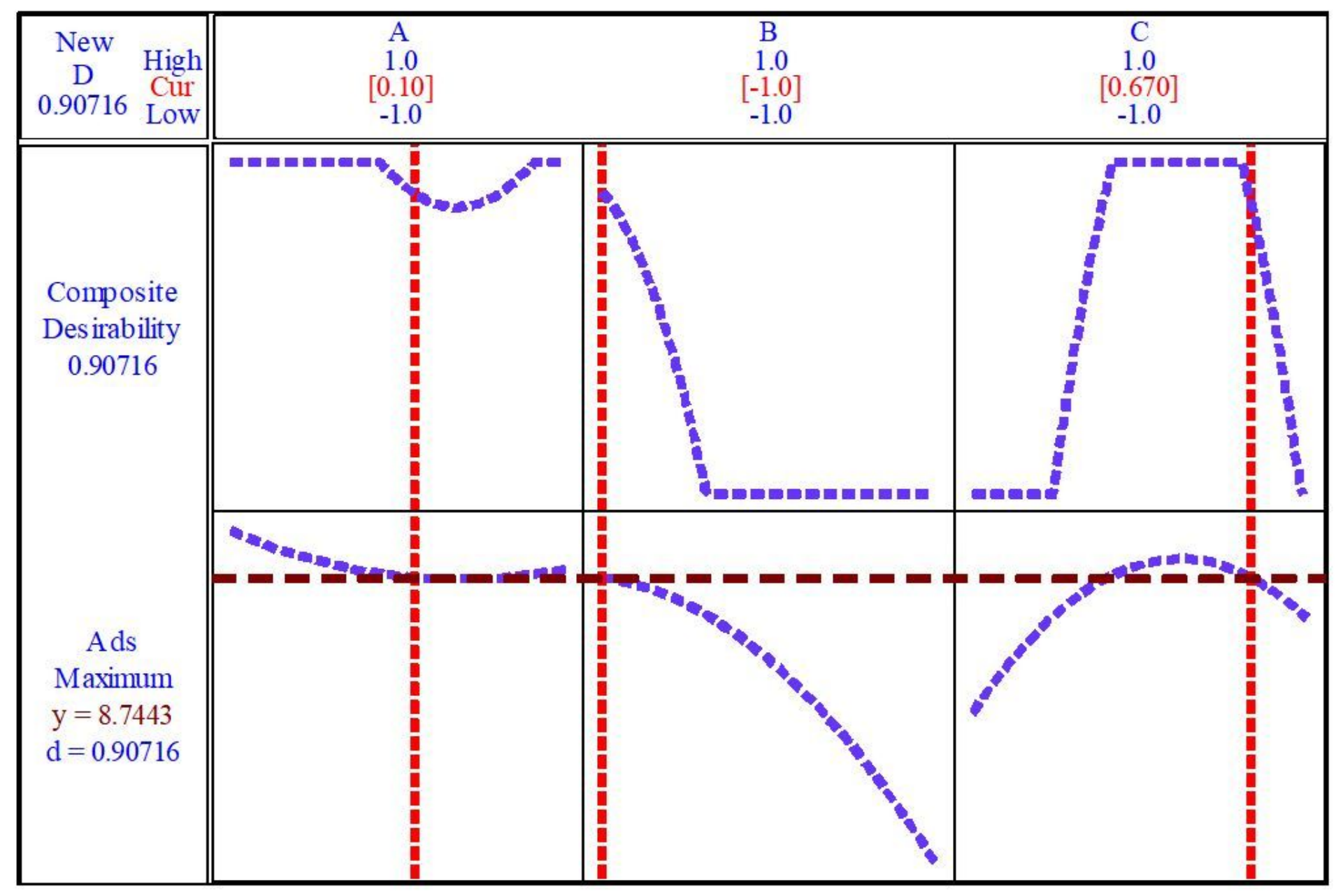

Figure 12

Optimization plots for arsine gas adsorption of Zn-MOF using RSM. 


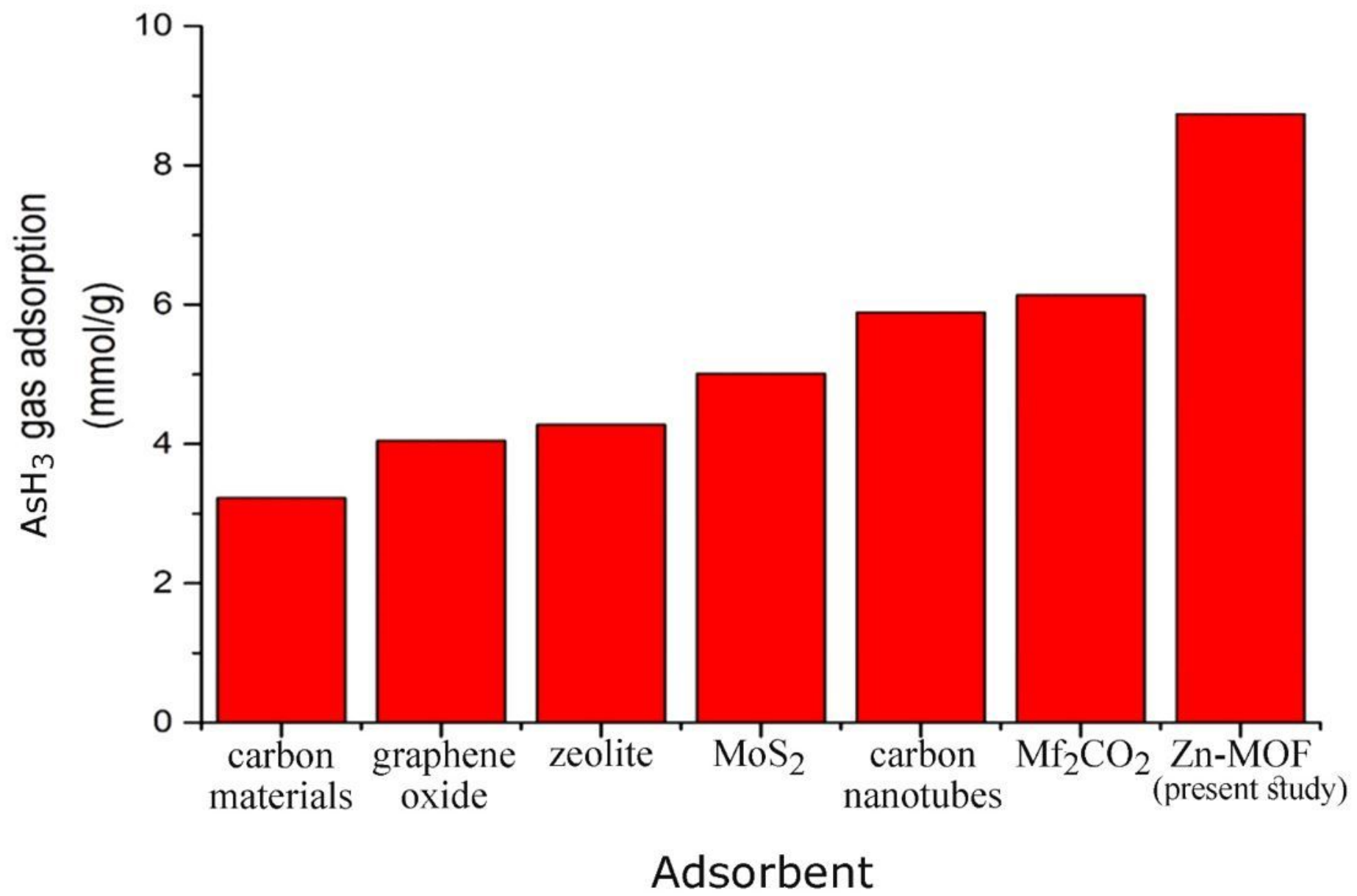

Figure 13

Comparing arsine gas adsorption by Zn-MOF prepared in this work with other compounds. 